\title{
Clinical repercussions and epidemiological considerations of supernumerary canines: A 26 case series
}

\author{
Jorge Cortés-Bretón-Brinkmann ${ }^{1}$, Natalia Martínez-Rodríguez ${ }^{2}$, Cristina Barona-Dorado ${ }^{3}$, María Martín- \\ Ares ${ }^{4}$, Javier Sanz-Alonso ${ }^{5}$, María-Jesús Suárez-García ${ }^{6}$, Juan-Carlos Prados-Frutos ${ }^{7}$, José-María \\ Martínez- González ${ }^{8}$
}

${ }^{1} \mathrm{DDS}, \mathrm{MsC}$, PhD.Assistant Professor of oral prosthodontics and oral surgery School of dentistry, Complutense University of Madrid; Oral Surgeon, Hospital Virgen de La Paloma, Madrid, Spain

${ }^{2}$ DDS,MsC, PhD. Assistant Professor of oral surgery School of dentistry, Complutense University of Madrid; Oral Surgeon, Hospital Virgen de La Paloma, Madrid, Spain

${ }^{3} \mathrm{DDS}, \mathrm{MsC}, \mathrm{PhD}$. Associate Professor of oral surgery, School of dentistry, Complutense University of Madrid, assistant director Department of Oral and dental Implant Surgery, Hospital Virgen de La Paloma, Madrid, Spain

${ }^{4}$ DDS, MsC, PhD. Assistant Professor of oral surgery School of dentistry, Complutense University of Madrid; Oral Surgeon, Hospital Virgen de La Paloma, Madrid, Spain

${ }^{5}$ DDS, MsC,PhD. Associate Professor of oral surgery, School of dentistry, Complutense University of Madrid. Oral Surgeon, Hospital Virgen de La Paloma, Madrid, Spain

${ }^{6} \mathrm{DDS}, \mathrm{MD}, \mathrm{PhD}$. Full Professor of oral prosthodontics, School of dentistry, Complutense University of Madrid

${ }^{7}$ DDS, MD, PhD. Full professor of oral surgery, School of dentistry, King Juan Carlos University of Madrid

${ }^{8} \mathrm{DDS}, \mathrm{MD}, \mathrm{PhD}, \mathrm{MDV}$. Full professor of maxillofacial surgery, School of dentistry, Complutense University of Madrid; and the head, Department of Oral and dental Implant Surgery, Hospital Virgen de La Paloma, Madrid, Spain

Correspondence:

Department of Dental Clinical Specialties

Faculty of Dentistry

Complutense University of Madrid, Spain

brinkmann55@hotmail.com

Received: 08/02/2019 Accepted: 29/05/2019
Cortés-Bretón-Brinkmann J, Martínez-Rodríguez N, Barona-Dorado C, Martín-Ares M, Sanz-Alonso J, Suárez-García MJ, Prados-Frutos JC, Martínez- González JM. Clinical repercussions and epidemiological considerations of supernumerary canines: A 26 case series. Med Oral Patol Oral Cir Bucal. 2019 Sep 1;24 (5):e615-20.

http://www.medicinaoral.com/medoralfree01/v24i5/medoralv24i5p615.pdf

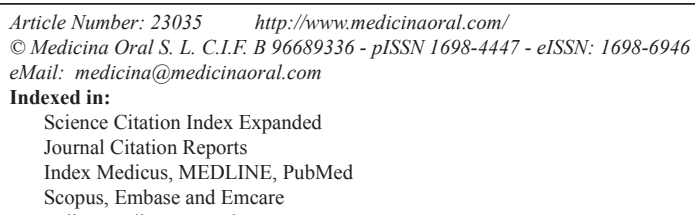

Indice Médico Español

\begin{abstract}
Background: To establish the prevalence of supernumerary canines (SNC) in a sector of the population of Madrid (Spain), as well possible complications associated with this unusual developmental variation.

Study design: This observational study was performed between 2005 and 2017, among 21,615 patients seeking dental treatment at the Faculty of Dentistry, Complutense University of Madrid (Spain), and at the Virgen de la Paloma Hospital, Madrid (Spain); 22 patients with 26 SNCs were diagnosed. These 22 patients underwent clinical and radiological exploration, registering patient data.
\end{abstract}


Results: SNCs presented a prevalence of $0.10 \%$ of the study population. The supernumerary teeth (SNT) were located in the upper maxilla more frequently (61.54\%) than the mandible (38.46\%). 69.23\% were found to be impacted, also causing the impaction of the permanent canine in $53.85 \%$ of these cases. In $15.38 \%$, follicular expansion $>3 \mathrm{~mm}$ was observed. SNCs were associated with other SNT in only four patients.

Conclusions: Despite of the fact that the SNCs are usually diagnosed casually in the course of radiological exploration, in the present study over half of them (53.85\%) caused impaction of the permanent canine. Early diagnosis allows optimal patient management and treatment planning, with intervention at an appropriate time to prevent complications in development and so reduce later treatment need.

Key words: Supernumerary canines, case-series, pathology, repercussions, epidemiological considerations.

\section{Introduction}

Hyperdontia, hypergenesis or the presence of supernumerary teeth (SNT) is defined as the existence of teeth in excess of normal dentition (1). Orhan (2) defines the presence of SNT as total teeth numbering over 20 in temporary dentition and over 32 in permanent dentition. It is important to specify any excess tooth/teeth in specific groups of teeth rather than the total dental formula as SNT may coexist in combination with dental agenesis. Classically, multiple hyperdontia has been associated with a number of genetic syndromes and/or congenital craniofacial anomalies (3). Cleidocranial dysplasia, Gardner's syndrome, Ehlers-Danlos syndrome (4), Ellis van Creveld syndrome (5), Tricho rhino-phalangeal syndrome, Fabry-Anderson syndrome, Down's syndrome, or cleft lip and/or cleft palate are some of the entities cited in the literature as being related to multiple hyperdontia. Although SNT are a developmental variation, they are relatively frequent (6), (with a prevalence of $0.15-3.9 \%$ ), but the incidence of supernumerary canines in absence of syndromes/conditions is exceptional. Moreover, an SNC can produce esthetic and functional disorders $(7,8)$.

The etiology of supernumerary teeth within the population is multifactorial with evidence of chromosomal, polygenic, single gene and major environmental influences in this complex etiology; different factors may exert a major influence in different individuals (9). Variation in outcome in a developmental process, such as the formation of the dentition, enables adaptation to different environments. Tooth number, size and shape are determined during the initiation and morphogenetic stages of dental development. The molecular evidence of repetitive signalling throughout initiation and morphogenesis is reflected clinically in the association of anomalies of number, size and shape.

The present study set out to determine the prevalence of supernumerary canines (SNCs) in a sector of the population of Madrid, as well as the possible complications associated with hypergenetic canines.

\section{Material and Methods}

The Ethics Committee of the Complutense University of Madrid approved this retrospective observational study protocol, which was carried out at the Faculty of Dentistry (Complutense University of Madrid, Spain) and the Virgen de la Paloma Hospital (Madrid, Spain). The study included a total of 21,615 patients seeking dental attention at the two study centers between 2005 and 2017. All had panoramic radiographs and periapical or occlusal radiographs obtained at the radiodiagnostic department at the Complutense University.

Whenever the presence of an SNC was discovered, the patient was referred to the Oral Surgery Service for examination. Twenty-two patients were registered presenting 26 SNC. Each patients' age and sex was recorded on a clinical data sheet, together with the eruption state of the permanent canine and radiological findings from periapical/occlusal and panoramic radiographs. Imagebased diagnosis established whether location was maxillary or mandibular, the morphology of the SNC (we establish the differential diagnosis between the primary canine and the supernumerary canine taking into account the specific features of the temporal teeth: colour, crown morphology and root length), the state of the follicular sac, and any association with other SNT.

When all data had been collected, they were entered on a spreadsheet (Ms-Excel) and exported to a statistical analysis software package (SPSS version 25.0 for Windows).

Statistical analysis consisted of univariate analysis (mean, standard deviation, median, etc.) and bivariate analysis to relate different variables and to analyze data variations, using the chi-squared test; statistical significance was established with a confidence interval (CI) of $95 \%$. $(p<0,05)$.

\section{Results}

-Univariate analysis

The study discovered 26 SNCs in 22 patients, representing a prevalence of $0.10 \%$ (CI 95\%: $-6,095 \%, 6,295 \%$ ) of the total population studied $(\mathrm{n}=21,615)$. Twelve cases corresponded to men (54.55\%) (CI 95\%: 34,3\%-73,7\%), and 10 to women (45.45\%) (CI 95\%:26,3\%-65,7\%), establishing a male to female ratio of 1.2:1. The age when patients were first diagnosed ranged from 7 to 77 years, with a mean diagnosis age of 28.0 years (CI 95\%:20,2-35,9 years). 
In 63,64\% (CI 95\%:42,87\%-81,07\%) of cases diagnosis occurred when patients were aged over 20 years. Of the whole sample, $61.54 \%$ (CI 95\%: 42,4\%-78,2\%) of SNCs were located in the upper maxilla, while $38.46 \%$ (CI 95\%:21,8\%-57,6\%) were in the mandible. The presence of two SNCs was observed in four patients, representing 18.18\% (CI 95\%:6,47\%-37,64\%) of the case sample. Over two thirds (69.23\%) of SNCs were found to be impacted (CI 95\%:50,2\%-84,2\%), while $30.77 \%$ (CI 95\%:15,8\%-49,8\%) had erupted (Table 1). The presence of SNCs caused eruption disorders of the permanent canines in 53.85\% of cases (CI 95\%:35,1\%-71,8\%). Radiological examination observed that follicle sacs presented expansion $>3 \mathrm{~mm}$ in only four cases, representing $15.38 \%$ of the sample (CI 95\%:5,4\%-32,5\%).

Analyzing morphology, 14 SNCs $(53.85 \%)$ (CI 95\%:35,1\%-71,8\%) presented supplemental morphology, while 12 presented heteromorphic morphology (46.15\%) (CI 95\%:28,2\%-64,9\%) representing a ratio of $1 / 0.86$.

Association with other SNT was found in four patients (18.18\%) (CI 95\%:6,47\%-37,64\%), noting the presence of two deciduous maxillary lateral incisors and two mandibular incisors.

-Bivariante analysis

Bivariate analysis did not identify any statistically significant differences $(p<0,05)$, which may be attributed to the sample size. Nevertheless it was possible to identify and analyze some relations between variables. A relation was identified between patients aged less than 20 years and impaction of the permanent canine ( $p=0.165$ ), causing eruption disorders in every case. Mandibular canines, although few, were more frequently associated with impaction and follicular expansion than maxillary SNCs $80 \%$ vs. $50 \%(p=0.350)$.

\section{Discussion}

The literature includes numerous studies of the prevalence of SNT. Authors such as Nazif et al (10), Davis (11) or Peltola (12) have produced a variety of works of research investigating hypergenesis in general, covering every type of supernumerary tooth (mesiodens, canines, premolars and molars). But studies limited to investigating SNCs alone are scarce and none to date have established a case series (10 or more patients presenting the same phenomenon). As far as the present authors are aware, the present case study of 26 SNCs in 22 patients could be the most extensive published in the literature to date (Table 1).

The prevalence of SNCs obtained from a population of 21,615 patients, was $0.10 \%$ (22 patients. CI 95\%: $-6,095 \%, 6,295 \%)$. This percentage is slightly higher than the prevalence obtained by other authors $(0-0.04 \%)$ $(11,13,14)$. The discrepancy can probably be explained by the small number of cases of this type of hyperdon- tia reported in previous studies. Stafne (15) only found three SNCs among 441 patients with a total of 500 SNT. Stafne considered that denticles and odontomas were found more frequently in the canine region than SNCs. Rajab and Hamdan (16) diagnosed five SNCs among a total of 202 SNT (2.48\%), while Fernández Montenegro et al. (17) found four SNCs among 145 SNT (2.75\%). But Leco Berrocal et al. (18) obtained a higher percentage in their sample (4.17\%), although the study only included 24 SNT. Other authors such as Davis (11), Harris and Clark (19) or Burgess (20) not discover any SNCs in their respective studies.

The discovery of hyperdontia is more frequent in men than women in a proportion established by most researchers as around 2:1. This ratio can reach a value of 6.5:1 in the case of Eastern Asian populations (11). The present study did not find significant differences in the male/female proportion, which was 1.2:1. This datum is not comparable to other studies of SNCs, due to a lack of published information.

According to the literature, almost a third of patients with SNT present more than one (1) The presence of multiple SNT (multiple hyperdontia) in absence of associated syndromes and/or systemic conditions is an exceptional finding (21). In the present study, of the 22 patients with SNCs, 14 (63.64\%) (CI 95\%:42,87\%-81,07\%) presented a single SNC and four presented two SNCs. Four patients (18.18\%) (CI 95\%:6,47\%-37,64\%) presented one SNC with another ST of different dental type (two patients had a supernumerary deciduous maxillary lateral incisor and the other two had supernumerary mandibular lateral incisors) (Fig. 1). Salcido-García et al. (6) discovered a case of four SNCs. Türkkahraman et al. (7) described a rare case of a twelve-year-old boy with bilateral supernumerary maxillary permanent canines. Hume (22) reported a case of a 17-year-old male with three SNCs (two mandibular and one maxillary).

According to the literature, SNT occur more frequently in the upper maxilla than the mandible, at a proportion of 5:1 or 10:1 according to different authors $(1,23)$. The present results coincide with most other studies with most of the SNCs located in the upper maxilla $(61,54 \%)$ (CI 95\%:42,4\%-78,2\%) (Fig. 2). Stafne (15) and Rajab and Hamdan (16) obtained similar results to the present study finding $66.66 \%$ and $60.0 \%$ (respectively) of canines in the upper maxilla. But Fernández Montenegro et al. (17) observed a higher percentage of SNCs in the mandible (75\%). Such disparities in results can be explained by the small numbers of SNCs reported in research. As a general rule, the diagnosis of SNT usually occurs as a casual radiological discovery as more often than not these teeth are impacted. Most authors consider that SNT are impacted in between 75 and $80 \%$ of cases $(1,24)$. The results of the present study differ slightly as impacted SNCs only represented $69.23 \%$ (CI 
Table 1: Data of 24 SNCS and their relation with eruption disorders and follicular sac expansion/enlargement $>3 \mathrm{~mm}$.

\begin{tabular}{|c|c|c|c|c|c|c|c|c|c|}
\hline $\begin{array}{l}\text { Patient } \\
\text { number }\end{array}$ & $\begin{array}{l}\text { Number } \\
\text { of SNCs. }\end{array}$ & Sex & Age & $\begin{array}{c}\text { SNC Eruption } \\
\text { status }\end{array}$ & Location & Morphology & $\begin{array}{l}\text { PC Erup- } \\
\text { tion status }\end{array}$ & $\begin{array}{l}\text { FSE } \\
>3 \mathrm{~m}\end{array}$ & $\begin{array}{c}\text { Other associated } \\
\text { SNT besides } \\
\text { SNC }\end{array}$ \\
\hline 1 & 1 & $\mathrm{~F}$ & 27 & Impacted & Max & Suppl & Impacted & yes & no \\
\hline 2 & 1 & M & 8 & Impacted & Mand & Suppl & Impacted & No & yes \\
\hline 3 & 2 & $\mathrm{~F}$ & 26 & $\begin{array}{l}\text { Erupted } \\
\text { Erupted }\end{array}$ & Max & Hetero & $\begin{array}{l}\text { Erupted } \\
\text { Erupted }\end{array}$ & no & no \\
\hline 4 & 1 & M & 75 & Erupted & Mand & Suppl & Erupted & no & no \\
\hline 5 & 1 & M & 40 & Impacted & Max & Hetero & Impacted & no & yes \\
\hline 6 & 1 & M & 27 & Erupted & Max & Hetero & Erupted & no & no \\
\hline 7 & 2 & $\mathrm{~F}$ & 29 & $\begin{array}{l}\text { Impacted } \\
\text { Impacted }\end{array}$ & Max & Suppl & $\begin{array}{l}\text { Erupted } \\
\text { Impacted }\end{array}$ & no & no \\
\hline 8 & 1 & M & 25 & Impacted & Mand & Hetero & Erupted & yes & no \\
\hline 9 & 1 & M & 19 & Impacted & Max & Suppl & Impacted & no & no \\
\hline 10 & 1 & $\mathrm{~F}$ & 17 & Impacted & Mand & Suppl & Impacted & no & no \\
\hline 11 & 1 & $\mathrm{~F}$ & 18 & Impacted & Mand & Hetero & Impacted & no & no \\
\hline 12 & 1 & $\mathrm{~F}$ & 25 & Impacted & Max & Suppl & Impacted & yes & no \\
\hline 13 & 1 & M & 7 & Impacted & Mand & Suppl & Impacted & no & yes \\
\hline 14 & 2 & $\mathrm{~F}$ & 24 & $\begin{array}{l}\text { Erupted } \\
\text { Erupted }\end{array}$ & Max & Hetero & $\begin{array}{l}\text { Erupted } \\
\text { Impacted }\end{array}$ & no & no \\
\hline 15 & 1 & M & 77 & Erupted & Mand & Suppl & Erupted & no & no \\
\hline 16 & 1 & M & 45 & Impacted & Max & Hetero & Impacted & no & no \\
\hline 17 & 1 & M & 22 & Erupted & Max & Hetero & Erupted & no & no \\
\hline 18 & 2 & $\mathrm{~F}$ & 24 & $\begin{array}{l}\text { Impacted } \\
\text { Impacted }\end{array}$ & Max & Suppl & $\begin{array}{l}\text { Erupted } \\
\text { Erupted }\end{array}$ & no & no \\
\hline 19 & 1 & M & 29 & Impacted & Mand & Hetero & Erupted & yes & no \\
\hline 20 & 1 & M & 18 & Impacted & Max & Suppl & Impacted & no & yes \\
\hline 21 & 1 & $\mathrm{~F}$ & 16 & Impacted & Mand & Suppl & Impacted & no & no \\
\hline 22 & 1 & $\mathrm{~F}$ & 19 & Impacted & Mand & Hetero & Impacted & no & no \\
\hline
\end{tabular}

Max: Maxillary supernumerary canine

Mand: Mandibular supernumerary canine

Suppl: Supplemental morphology

Hetero: Heteromorphic morphology

95\%:50,2\%-84,2\%) of the sample (30.77\% were erupted) (CI 95\%:15,8\%-49,8\%). Fernández Montenegro et al. (17) found only $50 \%$ of SNCs to be impacted, while Salcido-García et al. (6) report four impacted SNCs in their study.

SNCs tend to adopt the shape of the original canine. But sometimes they can be of smaller size (8). Of the 26 SNCs in the present study, 14 (53.85\%) (CI 95\%:35,1\%-
$71,8 \%$ presented supplemental morphology and 12 (46.15\%) (CI95\%:28,2\%-64,9\%) heteromorphic morphology. These results more or less coincide with those obtained by Férnández Montenegro et al. (17) who observed supplemental morphology in 50\% (two out of four SNCs). Others such as Türkkahraman et al. (7), Hume (22), Sasaki et al (25), and Stevenson (26) have reported clinical cases of SNCs with supplemental mor- 


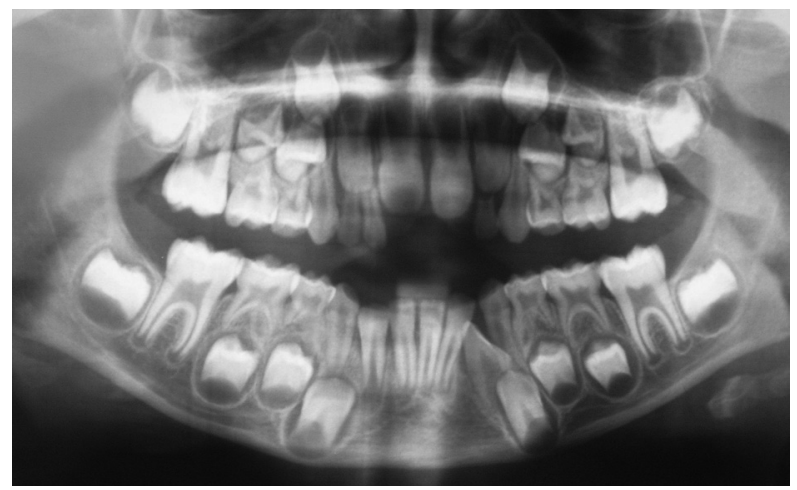

Fig. 1: Mandibular supernumerary canine in the third quadrant impeding the eruption of the canine. A supernumerary temporary lateral incisor can also be seen in the first quadrant.
Shetty and Sandler (29) and Ramakrishna and Lambade (30) report that cystic transformation is infrequent.

Over half of the SNCs in the present study (53.85\%) (CI 95\%:35,1\%-71,8\%) caused impaction of the permanent canine (Fig. 3). Fernández Montenegro et al. (17) identified mechanical-obstructive pathology in two out of four SNCs included in their study, although none presented cystic pathology. It is worth noting that in the present study all SNCs in patients aged younger than 20 years caused eruption disorders $(p=0.165)$. However, Sasaki et al. (25) reported a case of multiple hyperdontia in the canine and premolar regions in a 14-year-old boy, in which the two SNCs present were not expected to trigger the displacement or mechanical-obstructive

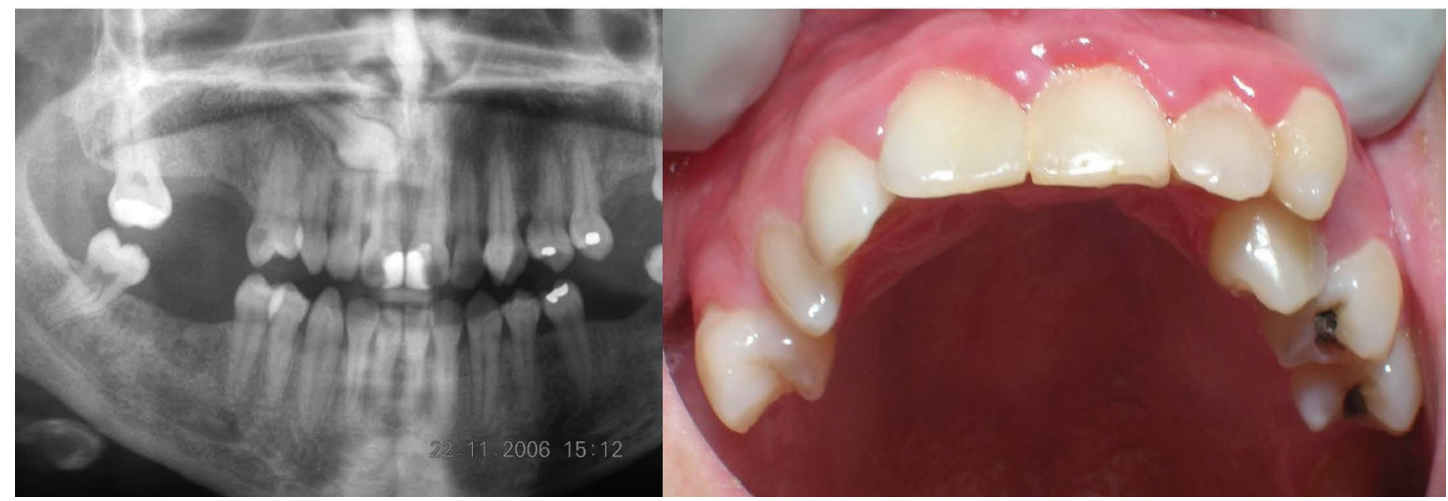

Fig. 2: Radiograph and clinical image showing supernumerary canines erupting in the first and second quadrants. In the first quadrant impaction of permanent canine and erupted supernumerary canine. In the second quadrant eruption of both canines (supernumerary and permanent).

phology; but Stafne's study (15) found three SNCs none of which were close to the normal size.

One of the present study's objectives was to analyze the clinical consequences of SNCs. Türkkahraman et al. (7) assert that an ST can produce esthetic and functional disorders. Nadal-Valldaura and Viader Codina (8) maintain that when impacted, SNCs may trigger the symptoms that typify impacted teeth in general. Follicular sac expansion/enlargement $>3 \mathrm{~mm}$ was evaluated as previous studies have considered this a relevant variable. Eliasson et al. (27) and Sewerin and von Wovern (28) studied follicular sac expansion $>3 \mathrm{~mm}$ in impacted mandibular third molars, concluding that although it was not common $-6 \%$ and $5.4 \%$ respectively - histological analysis identified the presence of follicular cysts in these cases. In the present study, $15.38 \%$ (CI 95\%:5,4\%-32,5\%) of SNCs presented follicular sac expansion $>3 \mathrm{~mm}$; however, we have no record of later follow-up monitoring to suggest further expansion of the follicular sacs involved. According to the scant literature available, in spite of the hypothetical relation between follicular sac expansion and its evolution into a follicular cyst, this can be considered unusual. Both

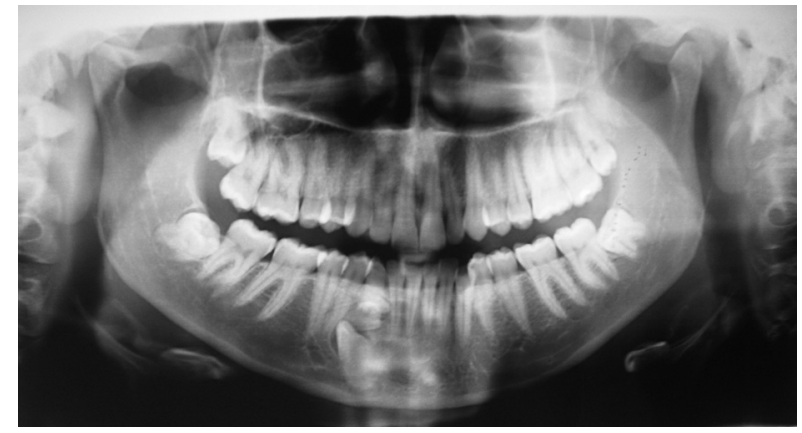

Fig. 3: Mandibular supernumerary canine in the fourth quadrant impeding the eruption of the canine.

pathology of the adjacent teeth.

In any case early diagnosis allows optimal patient management and treatment planning, with intervention at an appropriate time to prevent complications in development and so reduce later treatment need.

It is noteworthy the inherent limitations of our study related with the fact that the $95 \% \mathrm{CI}$ are large, what can be justified due to the small sample size.

This study analyzed the epidemiological characteristics 
of a case series of 26 SNCs. SNCs in absence of an associated syndrome or systemic condition are extremely rare and are normally diagnosed casually in the course of radiological exploration. Nevertheless, this type of hyperdontia is associated with a high percentage of pathology.

\section{References}

1. Russell KA, Folwarczna MA. Mesiodens-diagnosis and management of a common supernumerary tooth. J Can Dent Assoc. 2003;69:362-6

2. Orhan AI, Ozer L, Orhan K. Familial ocurrence of nonsyndromal multiple supernumerary teeth. A rare condition. Angle Orthod. 2006;76:891-7.

3. Mason C, Azam N, Holt RD, Rule DC. A retrospective study of unerupted maxillary incisors associated with supernumerary teeth. Br J Oral Surg. 2000;38:62-5.

4. Melamed Y, Barkai G, Frydman M. Multiple supernumerary teeth (MSNT) and Ehlers-Danlos syndrome (EDS): a case report. J Oral Pathol Med. 1994;23:88-91.

5. Hattab FN, Yassin OM, Sasa IS. Oral manifestations of Ellis-van Creveld syndrome: report of two siblings with unusual dental anomalies. J Clin Pediatr Dent. 1998;22:159-65.

6. Salcido-García JF, Ledesma-Montes C, Hernández-Flores F, Pérez D, Garcés-Ortiz M. Frequency of supernumerary teeth in Mexican population. Med Oral Patol Oral Cir Bucal. 2004;9:407-9.

7. Türkkahraman H, Yilmaz HH, Cetin E. A non-syndrome case with bilateral supernumerary canines: report of a rare case. Dentomaxillofac Radiol. 2005;34:319-21.

8. Nadal-Valldaura A. Study of supernumerary teeth. Rev Esp Estomatología. 1967;15:27-46.

9. Brook AH, Jernvall J, Smith RN, Hughes TE, Townsend GC. The dentition: theoutcomes of morphogenesis leading to variations of tooth number, size and shape. Aust Dent J. 2014;59:131-42.

10. Nazif MM, Ruffalo RC, Zullo T. Impacted supernumerary teeth: a survey of 50 cases. J Am Dent Assoc. 1983;106:201-4.

11. Davis PJ. Hypodontia and hyperodontia of permanent teeth in Hong Kong schoolchildren. Community Dent Oral Epidemiol. 1987; 15:218-20.

12. Peltola JS. A panoramatomographic study of the teeth and jaws of Finnish university students. Community Dent Oral Epidemiol. 1993;21:36-9.

13. McKibben DR, Brearley LJ. Radiographic determination of the prevalence of selected dental anomalies in children. ASDC J Dent Child. 1971;38:390-8.

14. Ramsaran AS, Barclay S, Scipio E, Ogunsalu C. Non-syndromal multiple buried supernumerary teeth: report of two cases from the English-speaking Caribbean and a review of the literature. West Indian Med J. 2005;54:334-6.

15. Stafne EC. Supernumerary teeth. Dental Cosmos 1932;74:653-9.

16. Rajab LD, Hamdan MA. Supernumerary teeth: review of the literature and a survey of 152 cases. Int J Paediatr Dent. 2002;12:24454.

17. Fernández Montenegro P, Valmaseda Castellón E, Berini Aytés L, Gay Escoda C. Retrospective study of 145 supernumerary teeth. Med Oral Patol Oral Cir Bucal. 2006;11:E339-44.

18. Leco Berrocal MI, Martín Morales JF, Martínez González JM. An observational studyof the frequency of supernumerary teeth in a population of 2000 patients. Med Oral Patol Oral Cir Bucal. 2007;12:E 134-8.

19. Harris EF, Clark LL. An epidemiological study of hyperodontia in American blacks and whites. Angle Orthod. 2008;78:460-5.

20. Burgess JO. A panoramic radiographic analysis of Air Force basic trainees. Oral Surg Oral Med Oral Pathol. 1985;60:113-7.

21. Saini T, Keene Jr JJ, Whetten J. Radiograph diagnosis of supernumerary premolars: case reviews. ASDC J Dent Child. 2002;69:18490.
22. Hume WJ. Supplemental canines. A case report. J Dent. 1973;1:261-2.

23. Solares R, Romero MI. Supernumerary premolars: a literature review. Pediatric Dent. 2004;26:450-8.

24. Martínez-González JM, Brinkmann JC, Calvo-Guirado JL, Arias-Irimia O, Barona-Dorado C. A clinical epidemiological analysis of a sample of 73 supernumerary premolars. J Am Dent Assoc. 2010;141:1435-41.

25. Sasaki H, Funao J, Morinaga H, Nakano K, Ooshima T. Multiple supernumerary teeth in the maxillary canine and mandibular premolar regions: a case in the postpermanent dentition. Int J Paediatr Dent. 2007;17:304-8.

26. Stevenson W. Supernumerary canines. Report of an unusual case. Br Dent J. 1965;118:257-8.

27. Eliasson S, Heimdahl A, Nordenram A Pathological changes related to long-term impaction of third molars. A radiographic study. Int Oral Maxillofac Surg. 1989;18:210-2.

28. Sewerin I, von Wowern N. A radiographic four-year follow-up study of asymptomatic mandibular third molars in young adults. Int Dent J. 1990;40:24-30.

29. Shetty R, Sandler PJ. Keeping your eye on the ball. Dent Update. 2004;31:398-402.

30. Ramakrishna A, Lambade P. Dentigerous cyst associated with ectopic canine and a supernumerary tooth: a rare occurrence. J Surg Tech Case Rep. 2013;5:85-8.

\section{Conflict of interest}

Authors do not have any conflict of interest. 